\title{
Model of The Group Guidance Service Design Using The Cinema Therapy Method in Helping Student Achievement of Development Tasks
}

(4) (9) This is an open access article distributed under the Creative Commons Attribution License

CC-BY-NC-4.0 (C2020 by author (https://creativecommons.org/licenses/by-nc/4.0/).

(Received. Februari-20ZI; Reviewed: Maret-202I; Accepted: April-20ZI;

Available anline. April-2021; Published: April-2021)

Hesti Permata Sari'1, Fitria Kasih', Citra Imelda Usman ${ }^{3}$ 1Prodi Bimbingan dan Konseling, STKIP PGRI

Sumatera Barat

Email:

hestipermatasari96@gmail.com 2Prodi Bimbingan dan Konseling, STKIP PGRI

Sumatera Barat

Email:

fitriakasih20@yahoo.co.id

3Prodi Bimbingan dan

Konseling, STKIP PGRI

Sumatera Barat

Email:

citraimelda08@gmail.com
Abstract. This study aims to determine the effectiveness of The research objectives describe:1) The task profile of students' developmental achievement in class XI SMAN 3 Mukomuko. 2) Implementation of group guidance in helping the achievement of developmental tasks carried out by the Guidance and Counseling Teacher. 3) The group guidance service design model using the cinema therapy method in helping the achievement of student developmental tasks. This study uses a mixed method. Dataanalysis techniques for Development Task Inventory (ITP). While qualitative research,techniques used in data processing through data reduction,data presentation and conclusion drawing. Based on the results of research the following conclusions can be drawn: 1) The profile of the task of achieving the development of students in class XI of SMAN 3 Mukomuko seen from the Inventory of Development Tasks is generally at the level of self-awareness. 2) Implementation of group guidance in assisting the achievement of developmental tasks carried out by the Guidance and Counseling Teacher,providing monotonous group guidance, discussions, homeroom. 3) The design model of group guidance services using the cinema therapy method in helping the achievement of student developmental tasks. Based on the results of the research,it can be recommended that the Guidance and Counseling Teachers be able to apply 


\section{A Indanesian Journal of School Counseling: Theory. Application and Development Volume I Nomar I Tahun 2021. Pages 70-80 p-ISSN: 2775-1708 \& e-ISSN: 2775-555X Homepage: https://ojs.unm.ac.id/ijosc DDI: https://dai.org/I0.26850/ijosc.vlil.19982}

the group guidance service design model using the cinema therapy method.

Keyword: Model Group Guidance, Cinema Therapy Method, Development Tasks

Abstrak. Tujuan penelitian mendeskripsikan: 1) Profil tugas pencapain perkembangan peserta didik di kelas XI SMAN 3 Mukomuko, 2) Pelaksanaan bimbingan kelompok dalam membantu pencapaian tugas perkembangan yang dilakukan Guru Bimbingan dan Konseling. 3) Model rancangan layanan bimbingan kelompok dengan menggunakan metode cinema therapy dalam membantu pencapaian tugas perkembangan peserta didik. Penelitian ini menggunakan mixed method (kuantitatif) tentang profil tugas pencapain perkembangan peserta didik sedangkan (kualitatif) tentang pelaksanaan bimbingan kelompok dalam membantu pencapaian tugas perkembangan yang dilakukan Guru Bimbingan dan Konseling. Teknik analisis data Inventori Tugas Perkembangan (ITP). Sedangkan penelitian kualitatif, teknik yang digunakan dalam pengolahan data melalui reduksi data, penyajian data dan penarikan kesimpulan. Berdasarkan hasil penelitian dapat diambil kesimpulan sebagai berikut: 1) Profil tugas pencapain perkembangan peserta didik di kelas XI SMAN 3 Mukomuko dilihat dari Iventori Tugas Perkembangan pada umumnya berada pada tingkat sadar diri. 2) Pelaksanaan bimbingan kelompok dalam membantu pencapaian tugas perkembangan yang dilakukan Guru Bimbingan dan Konseling memberikan bimbingan kelompok monoton, diskusi, homeroom 3) Model rancangan layanan bimbingan kelompok dengan menggunakan metode cinema therapy dalam membantu pencapaian tugas perkembangan peserta didik. Berdasarkan hasil penelitian dapat direkomendasikan kepada Guru Bimbingan dan Konseling agar mampu menerapkan model rancangan layanan bimbingan kelompok 
Kata Kunci: Model Bimbingan Kelompok, Metode Cinema Therapy, Tugas Perkembangan

\section{PENDAHULUAN}

Perkembangan dimana suatu tahap bagi remaja dimana pada tahap perkembangan remaja memilki beberapa tahap perkembangan untuk menjadi seorang remaja yang lebih baik secara sistematis dan berlangsung terus menerus pada tahapan kehidupan remaja. Perkembangan remaja adalah proses ke tingkat yang lebih baik seorang remaja. Menurut Yusuf (2005: 15) perkembangan adalah proses perubahan ke tingkat yang lebih baik dan berlangsung secara terus menerus, baik dari fisik dan psikis.

Tugas perkembangan peserta didik adalah tugas yang harus dipenuhi bagi peserta didik. Havighurst (Putra, 2017: 27) menyatakan ada beberapa tugas perkembangan yang harus tercapai bagai peserta didik. Tugas perkembangan peserta didik antara lain peserta didik mampu membina hubungan baik dengan lawan jenis laki-laki atau pun perempuan, peserta didik mampu membentuk emosional kepada lingkungan keluarga dan orang lain.

Kartadinata, dkk (2003: 6-9) menyatakan tugas perkembangan peserta didik merupakan suatu tugas yang harus dicapai dengan baik sesuai dengan tingkat perkembangan peserta didik. Perkembangan peserta didik memiliki beberapa aspek perkembangan diantaranya: (1) Landasan religius, (2) landasan perilaku, (3) kematangan emosi, (4) kematangan intelektual, (5) kesadaran tanggung jawab, (6) peran sosial antara pria dan wanita, (7) penerimaan diri, (8) kemandirian perilaku ekonomis, (9) wawasan kesiaapan karir, (10) kematangan hubungan dengan teman sebaya, (11) persiapan diri untuk hidup berkeluarga.

Menurut Prayitno (Putra, 2017:32) menyatakan bahwa bimbingan kelompok yaitu suatu aktifitas yang ada pada bimbingan konseling dimana aktifitas tersebut dilakukan oleh Guru Bimbingan dan Konseling sebagai pemimpin kelompok dan peserta didik sebagai anggota kelompok. Selanjunya Pemimpin Kelompok dan Anggota Kelompok membahas sebuah topik melalui dinamika kelompok. Layanan bimbingan kelompok ini dapat membantu peserta didik dalam pengembangan potensi yang dimiliki dan kemampuan untuk beinteraksi dengan keluarga dan orang lain atau masyarakat.

Pelaksanan bimbingan kelompok dengan menggunakan metode cinema therapy dapat mempermudah pemimpin kelompok dalam menyampaikan tujuan kegiatan kepada anggota kelompok. Cinema therapy adalah proses penggunaan 
terapi sebagai motivasi untuk meningkatkan wawasan peserta didik (Setyawati, 2018: 6).

Berdasarkan observasi yang peneliti lakukan kepada peserta didik pada September 2019, peneliti menemukan bahwa adanya peserta didik yang tidak tercapai tugas perkembangannya, yang ditandai dengan adanya peserta didik yang kurang bisa menerima kenyataan perubahan fisik berupa badan terlalu besar atau kecil, peserta didik kurang akan kedasaran dalam mengerjakan tugas yang diberikan oleh guru di kelas, peserta didik ditemukan kecakapan intelektual yang kurang baik, peserta didik kurang memiliki rasa percaya diri mengikuti layanan bimbingan kelompok, serta guru bimbingan dan konseling yang belum melaksanakan layanan bimbingan kelompok dengan menggunakan metode bervariasi.

Berdasarkan wawancara yang peneliti lakukan pada 11 November 2019 di SMAN 3 Mukomuko Kabupaten Mukomuko dengan dua guru bimbingan dan konseling, wali kelas XI IPS 1 SMAN 3 Mukomuko Kabupaten Mukomuko, peneliti mendapatkan informasi bahwasanya adanya tugas perkembangan peserta didik yang tidak tercapai, kurangnya terlaksana layanan bimbingan kelompok, peserta didik kurang memiliki rasa percaya diri mengikuti layanan bimbingan kelompok, guru bimbingan dan konseling yang belum melaksanakan layanan bimbingan kelompok dengan menggunakan metode bervariasi. Maka dari itu peneliti mencoba rancangan layanan bimbingan kelompok dengan menggunakan metode cinema therapy dapat membantu pencapaian tugas perkembangan peserta didik.

Berdasarkan uraian permasalahan tersebut maka penenliti tertarik untuk membantu perkembangan peserta didik dengan menggunakan layanan bimbingan kelompok dengan metode cinematherapy, maka peneliti mencoba untuk menyusun penelitian melalui sebuah penelitian yang berjudul "Model RancanganLayanan Bimbingan Kelompok dengan Menggunakan Metode Cinema Therapy dalam Membantu Pencapaian Tugas Perkembangan Peserta Didik (Studi Deskriptif Analisis di Kelas XI IPS 1 SMAN 3 Mukomuko).

Oleh karena itu peneliti ini bertujuan untuk model rancanganlayanan bimbingan kelompok dengan menggunakan metode cinema therapy dalam membantu pencapaian tugas perkembangan peserta didik.

\section{METODE}

Penelitian ini didesian menggunakan mixed method. Menurut Mulyadi, dkk (2019: 150) penelitian ini merupakan campuran teknik kualitatif dan kuantitatif, 
Indonesian Journal of School Counseling: Theory, Application and Development Volume I Nomar I Tahun 2021. Pages 70-80

p-ISSN: 2775-1708 \& e-ISSN: 2775-555X

Homepage: https://ojs.unm.ac.id/ijosc

DDI: https://dai.org/I0.26858/ijosc.vlil.19982

seperti mencampurkan observasi dan wawancara (data kualitatif) dengan metode survey tradisional (data kuantitatif).

Instrumen yang digunakan adalah inventori tugas perkembangan (ITP). Menurut Wahyuni (Pratiwi, 2019: 3)iventori tugas perkembangan (ITP) merupakan instrumen yang digunakan untuk memahami tingkat perkembangan individu. Populasi penelitian berjumlah 27 orang. Teknik pengambilan sampel purposive sampling dengan jumlah sampel sebanyak 27 peserta didik. Pengolahan inventori tugas perkembangan dapat mengtahui profil tugas perkembangan peserta didik

Menurut Bungin (2018: 107) “Purposive sampling merupakan cara untuk menentukan informan dalam penelitian kualitatif, yaitu penentuan kelompok yang menjadi informan dalam penelitian".Penelian ini mengkaji tentang model rancangan layanan bimbingan kelompok dengan menggunakan metode cinema therapy dalam membantu pencapaian tugas perkembangan peserta didik sehingga peneliti menentukan informan penelitian berdasarkan pertimbanganpertimbangan tertentu sesuai dengan masalah yang dikaji. Populasi penelitian 3 orang. Alat pengumpul data yang digunakan wawancara. Menurut Riduwan (2006: 74) "Wawancara merupakan suatu penoman bagi peneliti untuk memperoleh informasi langsung dari sumbernya". Analisis data yang digunakan dalam penelitian ini adalah teknik deskriptif naratif tentang pelaksanaan bimbingan kelompok dalam membantu pencapain tugas perkembangan.

\section{HASIL DAN PEMBAHASAN}

\section{Hasil Profil Pencapaian Tugas Perkembangan}

Hasil penelitian ini dideskripsi data tentang model rancangan layanan bimbingan kelompok dengan menggunakan metode cinema therapy dalam membantu pencapaian tugas perkembangan peserta didik (Studi Deksriptif Analisis di kelas XI IPS 1 SMAN 3 Mukomuko) sehingga peneliti memutuskan untuk melakukan penelitian di SMAN 3 Mukomuko.

Berdasarkan hasil penelitian yang telah peneliti lakuka maka peneliti dapat menyampaikan bahwa tugas perkembangan peserta didik di kelas XI IPS 1 SMAN 3 Mukomuko, terlihat pada aspek landasan hidup regelius 4.58, pada aspek landasan perilaku etis 4.49, pada aspek kematangan emosional 4.46, pada aspek kematangan itelektual 4.56, pada aspek kesadaran tanggung jawab 4.32, pada aspek peran sosial sebagai pria dan wanita 4.56, pada aspek penerimaan diri dan pengembanganya 4.52, pada aspek kemandirian prilaku ekonomis 4.52, pada aspek wawasan persiapan karir 4.43, pasa aspek kematangan hubungan dengan 
teman sebaya 4.41, pada aspek persiapan diri untuk pernikahan dan hidup berkeluarga 4.53 .

\section{Pembahasan}

Berdasarkan hasil penelitian dapat dideskripsikan bahwa Model Rancangan layanan Bimbingan Kelompok dengan Menggunakan Metode Cinema Therapy dalam Membantu Pencapaian Tugas Perkembangan Peserta Didik (Studi Deskriptif Analisis di Kelas XI IPS 1 SMAN 3 Mukomuko) dengan masing sub variabel adalah sebagai berikut:

1) Tugas Perkembangan Peserta Didik di kelas XI IPS 1 SMAN 3 Mukomuko Berdasarkan Hasil Iventori Tugas Perkembangan (ITP) Peserta didik merupakan suatu proses untuk menuju ke arah yang lebih baik. Setiap proses yang dialami oleh peserta didik melalui tahap perkembangan bagi peserta didik.Berdasarkan temuan penelitian dapat di jelaskan tingkat perkembangan individu dalam aspek tugas perkembangan sebagai berikut:

a) Aspek Landasan Religius.

Secara umum tugas perkembangan peserta didik di SMAN 3 Mukomuko dari hasil pengolahan Iventori Tugas Perkembangan (ITP) pada landasan hidup religius berada tingkat perkembangan sadar diri 4.58.

b) Aspek Landasan Perilaku Etis.

Secara umum tugas perkembangan peserta didik di SMAN 3 Mukomuko dari hasil pengolahan Inventori Tugas Perkembangan (ITP) pada landasan perilaku etis berada pada tingkat perkembangan sadar diri 4.49.

c) Aspek Kematangan Emosional.

Secara umum tugas perkembangan peserta didik di SMAN 3 Mukomuko dari hasil Pengolahan Inventori Tugas Perkembangan (ITP) pada landasan kematangan emosional berada tinggkat sadar diri.

d) Aspek Kematangan Intelektual.

Secara umum tugas perkembangan peserta didik di SMAN 3 Mukomuko dari hasil pengolahan Inventori Tugas Perkembangan (ITP) pada landasan kematangan intelektual berada tingkat perkembangan sadar diri 4.46.

e) Aspek Kesadaran Tanggung Jawab.

Secara umum tugas perkembangan peserta didik di SMAN 3 Mukomuko dari hasil Pengolahan Inventori Tugas Perkembangan (ITP) pada landasan 
kesadaran tanggung jawab berada pada tingkat perkembangan sadar diri 4.32 .

f) Aspek Peran Sosial Sebagai Pria dan Wanita.

Secara umum tugas perkembangan peserta didik di SMAN 3 Mukomuko dari hasil pengolahan Inventori Tugas Perkembangan (ITP) pada landasan peran sosial sebagai pria dan wanita berada pada tingkat perkembangan sadar diri 4.56.

g) Penerimaan Diri dan Pengembanganya.

Secara umum tugas perkembangan peserta didik di SMAN 3 Mukomuko dari hasil pengolahan Inventori Tugas Perkembangan (ITP) pada landasan penerimaan diri dan pengembangannya berada pada tingkat sadar diri 4.52.

h) Aspek Kemandirian Perilaku Ekomonis.

Secara umum tugas perkembangan peserta didik di SMAN 3 Mukomuko dari hasil pengolahan Inventori Tugas Perkembangan (ITP) pada landasan kemandirian perilaku ekonomis berada tingkat sadar diri 4.52.

i) Aspek Wawasan dan Persiapan Karir. Secara umum tugas perkembangan peserta didik di SMAN 3 Mukomuko dari hasil Pengolahan Inventori Tugas Perkembangan (ITP) pada landasan wawasan dan persiapan karir berada pada tingkat sadar diri 4.43 .

j) Aspek Kematangan Hubungan dengan Teman Sebaya.

Secara umum tugas perkembangan peserta didik di SMAN 3 Mukomuko dari hasil pengolahan Inventori Tugas Perkembangan (ITP) pada landasan kematangan hubungan dengan teman sebaya berada pada tingkat perkembangan sadar diri 4.41.

k) Persiapan Diri untuk Pernikahan dan Hidup Berkeluarga.

Secara umum tugas perkembangan peserta didik SMAN 3 Mukomuko dari hasil pengolahan Inventori Tugas Perkembangan (ITP) pada Persiapan diri untuk pernikahan dan hidup berkeluarga berada pada tingkat perkembangan sadar diri 4.53 .

\section{Hasil tentang Temuan Penelitian Yang Telah Dilakukan Peneliti Maka Peneliti Dapat Membahas}

Berdasarkan temuan penelitian yang dilakukan dengan MT, J, N diperoleh bahwa bimbingan kelompok di SMAN 3 Mukomuko Guru Bimbingan dan Konseling pernah berikan layanan bimbingan kelompok pada peserta didik menggunakan metode monoton, diskusi, homeroom dan gemis pada saat bimbingan kelompok berlangsung agar peserta didik tidak bosan pada saat kegiatan bimbingan kelompok berlangsung, memberikan metode monoton, diskusi dan homeroom, sebagai seorang Guru Bimbingan dan Konseling harus lebih banyak belajar pada 
Indanesian Jaurnal of Schuol Counseling: Theory, Application and Development Volume I Nomar I Tahun 2021. Pages 70-80

p-ISSN: 2775-I70ם \& e-ISSN: 2775-555X

Homepage: https://ojs.unm.ac.id/ijosc

DDI: https://dai.org/I0.26858/ijasc.vlil.19982

zaman sekarang ini karena zaman saat ini sangat canggih media sosial. Guru Bimbingan dan Konseling harus bisa menggali gerak gerik peserta didik kita pada zaman sekarang ini dan Guru Bimbingan dan Konseling seharusnya lebih kreatif dan inofatif pada peserta didik, kendala yang ditemukan tidak adanya jam tatap muka bimbinga dan konseling di SMAN 3 Mukomuko. Maka layanan bimbingan dan konseling kurang maksimal terlaksanan di SMAN 3 Mukomuko terutama waktunya yang kurang untuk pemberian bimbingan kelompok.

Pada pertemuan pertama untuk melakukan bimbingan kelompok peserta didik kurang percaya diri untuk mengeluarkan pendapat pada saat bimbingan kelompok berlangsung. Pada saat pandemi covid 19 sekarang ini layanan bimbingan kelompok tidak berjalan dengan efektif. Terutama pada layanan bimbingan kelompok dan klasikal. Guru Bimbingan dan Konseling memberikan bimbingan kelompok lanjutan, dan memberikan metode dan topik yang lebih bervariasi pada peserta didik dan Guru Bimbingan dan Konseling memberi layanan bimbingan kelompok menggunakan media zoom pada saat pandemi covid 19 terutama bimbingan kelompok agar peserta didik tidak jenuh dalam belajar daring di rumah sebagai seorang Guru Bimbingan dan Konseling harus memberikan motivasi kepada peserta didik agar tidak jenuh dalam mengerjakan tugas yang diberikan setiap guru mata pelajaran, Guru Bimbingan dan Konseling harus bisa memberikan layanan bimbingan kelompok menggunakan media zoom pada peserta didik agar peserta didik tidak jenuh. Maka dari itu bimbingan kelompok dapat membantu peserta didik dalam menggatasi masalah yang dialami setiap peserta didik. Mahardika (2015: 54) menyatakan bahwa bimbingan kelompok merupakan sekumpulan peserta didik dijadikan satu kelompok.

\section{Model Layanan Bimbingan Kelompok}

Deskripsi Pelaksanaan Layanan Bimbingan Kelompok dengan menggunakan Metode Cinema Therapy. Tahap-tahap pelaksanaan layanan bimbingan kelompok dengan menggunakan metode cinema therapy antara lain:

a) Tahap pembentukan: adalah awalan dari kegiatan bimbingan kelompok sebelum memasuki ketahap peralihan. Pada tahap pembentukan pemimpin kelompok membuka kegiatan terlebih dahulu dan pemimpin kelompok 
memperkenalkan diri dan pemimpin meminta anggota kelompok juga memperkenalkan dirinya setelah itu pemimpin menjelasan pengertian bimbingan kelompok metode cinema therapy dan tujuan bimbingan kelompok metode cinema therapy, menjelaskan cara dan asas bimbingan kelompok metode cinema therapy, teknik khusus dan permainan penghangatan atau pengakraban.

b) Tahap peralihan: adalah tahap dimana kegiatan bimbingan kelompok akan dilaksanankan oleh Pemimpin kelompok. Pemimpin kelompok menjelasan kegiatan yang akan dilakukan pada bimbingan kelompok.metode cinema therapy topik tugas atau bebas.

c) Tahap Kegiatan: adalah inti dari bimbingan kelompok oleh Pemimpin Kelompok, Pemimpin Kelompok untuk membahas topik tugas dan bebas pada peserta anggota kelompok. Pada tahap kegiatan pemimpin kelompok menyayangkan film atau video pada anggota kelompok dan menyimak video secara bersama. Setelah film atau video ditayangkan pemimpin kelompok memintak partisipasi anggota kelompok terhadap film atau video yang ditayangkan oleh Pempimpin Kelompok.

d) Tahap Pengakhiran: merupakan kegiatan yang telah dilaksanankan oleh Guru Bimbingan dan Konseling. Pada tahap penutup Guru Bimbingan dan Konseling meminta peserta menyimpulkan hasil kegiatan yang telah dilaksanakan.

e) Tahap Evaluasi: merupakan tahap terakhir sebelum Pemimpin Kelompok dan Anggota Kelompok keluar dari pelaksanaan bimbingan kelompok Pemimpin Kelompok dan Anggota Kelompok.

a. Rancangan Program Layanan Bimbingan Kelompok dengan Menggunakan Metode Cinema Therapy.

Pada saat merancang program layanan bimbingan kelompok yang peneliti buat antara lain:

1. Komponen Program

a) Layanan dasar

Menurut Nurihsan (2009:27) layanandasar adalah layanan orientasi dilakukan Guru BK agar peserta didik mengenal bentuk layanan bimbingan kelompok dan mengetahui tentang yang layak peserta didik ketahui dalam mengetahui bagaimana bimbingan kelompok dapat membantu pencapaian tugas perkembangan peserta didik.

b) Layanan responsive 
Indanesian Jaurnal of Schuol Counseling: Theory, Application and Development Volume I Nomar I Tahun 2021. Pages 70-80

p-ISSN: 2775-1708 \& e-ISSN: 2775-555X

Homepage: https://ojs.unm.ac.id/ijosc

DDI: https://dai.org/I0.26858/ijosc.vlil.19982

Nurihsan (2009:33) mengemukakan bahwa layanan responsive adalah layanan yang bertujuan untuk membantu memenuhi kebutuhan yang dirasakan sangat penting oleh peserta didik saat ini.

c) Layanan peminatan dan perencanaan individual peserta didik

Nurihsan(2009:34) mengemukakan bahwa layanan yang bertujuan membantu seluruh peserta didik memuat dan mengimplementasi kanrencana-rencana pendidikan, karir, dan social pribadinya.

d) Dukungansisitem

Nurihsan (2009:35) mengemukakan bahwa dukungan system adalah kegiatan-kegiatan manajemen yang bertujuan untuk memantapkan, memelihara, danmeningkatkan program bimbingan secara menyeluruh melalui pengembangan professional; hubungan masyarakat yang lebihluas; manajemen program; penelitian dan pengembangan.

\section{Bidang Layanan}

a) Bidang pribadi berupa masalah pribadi peserta didik yang diungkap pada kegiatan layanan bimbingan kelompok

b) Bidang sosial berupa masalah interaksi sosial yang diungkap pada kegiatan layanan bimbingan kelompok.

c) Bidang belajar berupa masalah tugas yang diberikan setiap guru di sekolah.

d) Bidang karir berupa pemberian informasi tentang karir bagi peserta didik di sekolah melalui bimbingan kelompok.

e) Penentuan topik merupakan rician untuk lanjutan kegiatan bimbingan kelompok.

f) Fungsi layanan yaitu ada beberapa fungsi layanan dalam bimbingan kelompok seperti fungsi pengetahuan PK, fungsi preventif pembahas topik yang bisa membantu mengatasi masalah Anggota Kelompok, Dalam membuat desain RPL, konselor harus tahu dan paham fungi layanan yang mana yang menjadi tujuan yang ingin di capai peserta didik di lihat dari topik pembahasan dan aspek perkembangan.

g) Tujuan layanan yaitu berisi tentang tujuan dari kegiatan yang akan dilaksanakan oleh Pemimpin Kelompok untuk Anggota Kelompok.

h) Sasaran layanan kelas XI IPS 1.

i) Topik yang dibahas tentang Norma yang ada di SMAN 3 Mukomuko dan https://youtu.be/WDIYOgofoVO

j) Sumbermateri.

k) Metodecinema therapy. 
l) Mediayang digunakana saat melakukan bimbingan kelompok LCD, Neetbook, Video.

m) Pelaksanaan

n) Evaluasi yaitu hasil dari kegiatan yang telah dilaksanankan oleh Guru Bimbingan dan Konseling.

\section{SIMPULAN DAN SARAN}

Hasil dari penelitian yang telah peneliti lakukan tentang Model Rancangan Layanan Bimbingan Kelompok dengan Menggunakan Metode Cinema Therapy dalam Membantu Pencapaian Tugas Perkembangan Peserta Didik (Studi Deskriptif Analisis di Kelas XI IPS 1 SMAN 3 Mukomuko) dari hasil pengolahan Iventori Tugas Perkembangan dan wawancara dapat diambil kesimpulan sebagai berikut:

1. Profil pencapaian tugas perkembangan peserta didik di kelas XI IPS 1 SMAN 3 Mukomuko dilihat dari Iventori Tugas Perkembangan (ITP) peserta didik SMAN 3 Mukomuko pada umumnya berada pada tingkat sadar diri, seharusnya pada masa SMAN peserta didik telah mencapai tingkat perkembangan seksama dan individual dengan baik.

2. Pelaksanaan bimbingan kelompok dalam membantu pencapaian tugas perkembangan yang dilakukan Guru Bimbingan dan Konseling memberikan bimbingan kelompok monoton, diskusi, homeroom dan Guru Bimbingan dan Konseling diharapkan bisa lebih kreatif dalam pemberian layanan bimbingan kelompok lanjutan di SMAN 3 Mukomuko. Diharapkan Guru Bimbingan dan Konseling dapat menggunakan metode cinema therapy yang peneliti rancang.

3. Model rancangan layanan bimbingan kelompok dengan menggunakan metode cinema therapy dalam membantu pencapaian tugas perkembangan peserta didik dilihat dari penelitian yang peneliti lakukan di SMAN 3 Mukomuko Guru Bimbingan dan Konseling belum pernah melakukan layanan bimbingan kelompok menggunakan metode cinematherap, makapeneliti berharap agar Guru Bimbingan dan Konseling dapat menggaplikasikan metode cinema therapy yang peneliti rancangdi SMAN 3 Mukomuko.

Setelah menyimpulkan hasil penelitian, ada beberapa saran untuk beberapa pihak terkait dalam penelitian ini :

1. Kepada peserta didik, agar dapat menjadi pribadi yang lebih baik terutama untuk tugas perkembangan dengan baik. Khususnya pada kesadaran tanggung jawab. 
Indonesian Journal of School Counseling: Theory. Application and Development Volume I Nomar I Tahun 2021. Pages 70-80

p-ISSN: 2775-1708 \& e-ISSN: 2775-555X

Homepage: https://ojs.unm.ac.id/ijosc

DDII: https://dai.org/10.26858/ijasc.vlil.19982

2. Kepada Guru Bimbingan dan Konseling, agar dapat menerapkan model layanan bimbingan kelompok dengan menggunakan metode cinema therapy.

3. Kepada Kepala Sekolah, agar dapat menfasilitasi sarana dan prasarana yang dibutuhkan Guru Bimbingan dan Konseling di sekolah terutama pada kegiatan bimbingan dan konseling.

4. Anggota MGBK, agar dapat mengembangan kualitas dan kuantitas layanan yang ada dalam bimbingan dan konseling sesuai dengan perkembangan zaman. Khususnya layanan bimbingan kelompok.

5. Pengelola Program Studi Bimbingan dan Konseling, agar dapat meningkatkan layanan bimbingan dan konseling terutama layanan bimbingan kelompok dengan berbagai metode termasuk metode cinema therapy.

6. Dosen Pengampu Mata Kuliah Pelayanan Bimbingan Kelompok, agar dapat menerapkan layanan bimbingan kelompok metode cinema therapy kepada mahasiswa yang belajar pelayanan bimbingan kelompok

\section{DAFTAR RUJUKAN}

Bungin, B. (2011). Penelitian Kualitatif. Jakarta: Prenada Media Group.

Kartadinata, dkk, 2003. Kubus Tugas Perkembangan: Suatu Model Rekabangun Tugas Perkembangan Bagi Kepentingan Bimbingan dan Konseling. Jurnal Bimbingan dan Konseling Volume Vl, No 11.

Nurihsan, A. J. (2009). Strategi layanan bimbingan dan konseling. Bandung: Refika Aditama.

Mahardika (2015). Pengembangan Program Bimbingan Kelompok Untuk Meningkatkan Kemampuan Siswa Dalam Mengelola Stres. Jurnal Konseling GUSJIGANG Vol. 2(1), 2460-1187.

Praitiwi dkk 2005. Tugas-tugas Perkembangan Remaja di SMA Negeri 1 Sejangkung. Journal counseling, 1, 1-8.

Putra, F. (2017). Ketercapaian Tugas-tugas Perkembangan Siswa SMA dan Siswa Pondok Pesantren .Jurnal Counseling Care, 1(1), 27-34.

Riduwan. (2006). Belajar Mudah Penelitian untuk Guru-Karyawan dan Peneliti Pemula. Bandung: Alfabeta. 
Indonesian Journal of School Counseling: Theory, Application and Development Volume I Nomar I Tahun 2021. Pages 70-80

p-ISSN: 2775-1708 \& e-ISSN: 2775-555X

Homepage: https://ojs.unm.ac.id/ijosc

DOl: https://dai.org/I0.26858/ijosc.vlil.19982

Setyawati, S. P. (2018). Pengaruh Teknik Cinema Therapydalam Bimbingan Kelompok untuk meningkatkan Disiplin Siswa Kelas Xi di Smkkartanegara Kediri Tahun Ajaran 2017/2018. 02(04).

Yusuf, A. M. 2005. Metodologi Penelitian (Dasar-dasar Penyelidikan Ilmiah). Padang:

UNP Press. 